\title{
O CRESCIMENTO E DESENVOLVIMENTO DE CRIANÇAS NA FAIXA ETÁRIA DE 12 A 48 MESES EM CRECHE NA PERIFERIA DA CIDADE DE RIBEIRÃO PRETO-SP.
}

\author{
GROWTH AND DEVELOPMENT OF 12 DO 48-MONTH-OLD INFANTS IN A DAY NURSERY AT THE \\ OUTSKIRTS OF RIBEIRÃO PRETO CITY-SP. \\ CRECIMIENTO Y DESARROLLO DE NIÑOS CON RANGO DE EDAD ENTRE LOS 12 Y LOS 48 MESES DE \\ EDAD, EN GUARDERÍAS INFANTILES DE LAS ZONAS PERIFÉRICAS DE LA CIUDAD DE RIBEIRÃO PRETO-
} $S P$.

\section{Alessandra Carvalho Carabolante ${ }^{1}$ Maria das Graças Carvalho Ferriani ${ }^{2}$}

\begin{abstract}
RESUMO: O objetivo deste estudo é conhecer e descrever o estado nutricional de crianças na faixa etária de 12 a 48 meses de idade, matriculadas em uma creche municipal situada na periferia da cidade de Ribeirão Preto-SP no ano de 2000. A pesquisa é de cunho descritivo e exploratório. A amostra constitui-se de 58 crianças matriculadas nessa instituição em que foi realizada avaliação do crescimento e desenvolvimento pela somatometria e realizado visita às famílias das crianças que apresentaram abaixo do Percentil 10 , considerado insatisfatório. Os resultados obtidos indicam que: $53,4 \%$ das crianças estão abaixo do P10, sendo que destas $48,3 \%$ encontram-se na faixa etária de 24 meses; $12 \%$ estão acima do Percentil 90 , sendo que o maior contingente está na faixa etária de 36 meses com $71,4 \%$, e $34,4 \%$ estão dentro do índice de normalidade. Todas as crianças são oriundas de famílias com renda mensal de 2 a 3 salários-mínimos, escolaridade entre primeiro e segundo grau incompleto e maioria desempregada. Os dados encontrados apontam que há necessidade de ser implantado um programa de educação para a saúde tanto para as famílias como para a equipe da creche.
\end{abstract}

\section{PALAVRAS CHAVES: crescimento e desenvolvimento infantil, creche, família.}

SUMMARY: This study aimed at knowing and describing the nutritional condition of 12 to 48-month-old infants, enrolled in a municipal day nursery at the outskirts of Ribeirão Preto-Sp in 2000. It is a descriptive and exploratory research. The sample was composed of 58 children enrolled in the institution. The growth and development of them were assessed by the somatometric system and the families of children presenting a percentile below 10 , considered unsatisfactory, were visited. Results obtained showed that $53.4 \%$ of the children were below P10, $48.3 \%$ of those being 24 months old. On the other hand, $12 \%$ of the children were above P90, $71.4 \%$ of those being 36 months old. The remnant $34.4 \%$ of them presented normal percentiles. All of them came from poor families, with monthly wages from 2 to 3 minimum wages, schooling between incomplete primary and secondary levels, most of them jobless. Data points out to the need of implementing a health educational program intended for both the families and the day nursery team.

KEYWORDS: infant's growth and development, day nursery, family.

RESUMEN: El objetivo de este estudio es conocer y describir el estado nutricional de niños con rango de edad entre los 12 y los 48 meses, matriculados en una guardería municipal ubicada en la zona periférica de la ciudad de Ribeirão Preto-SP, durante el año 2000. La investigación es del de tipo descriptivo y de reconocimiento. La muestra está formada por 58 niños matriculados en la mencionada institución ,en la cual se realizó la evaluación del crecimiento y desarrollo a través de la somatometría y la realización de visitas a las familias de los niños que presentaron un percentil por debajo del Percentil 10, lo cual es considerado insatisfactorio. Los resultados obtenidos indicaron que: un $53,4 \%$ de los niños están por debajo del P10, siendo que de estos niños, un $48,3 \%$ se encuentran en el rango de edad de 24 meses; un $12 \%$ están por sobre el Percentil 90 , siendo que el mayor grupo está en el rango de edad de los 36 meses con $71,4 \%$, y un 34,4\% están dentro del índice de normalidad. Todos los niños provienen de familias pobres, con una renta mensual de 2 a 3 sueldos-mínimos, con una escolaridad de enseñaza Básica y Media incompleta y la mayoría desempleados. Los datos encontrados apuntan a la necesidad de que se implante un programa de educación para la salud, no sólo para las famílias sino tambien para el equipo de la guardería.

TERMINOS CLAVES: crecimiento y desarrollo infantil, guardería, familia.

1 Aluna de graduação da Escola de Enfermagem de Ribeirão Preto da Universidade de São Paulo. E-mail: accets@bol.com.br. Bolsista Fundo de Cultura e Extensão Universitária.

${ }^{2}$ Enfermeira. Doutora em Enfermagem. Profa. Titular do Departamento de Enfermagem Materno-Infantil e Saúde Pública da Escola de Enfermagem de Ribeirão Preto da Universidade de São Paulo. Av: Bandeirantes, 3900 - Campus Universitário Cep: 14040-902 - Ribeirão Preto-SP, E-Mail : caroline@eerp.usp.br 


\section{INTRODUÇÃO}

A infância é uma das fases da vida onde ocorrem as maiores modificações físicas e psicológicas. Essas mudanças caracterizam o crescimento e desenvolvimento infantil, e precisam ser acompanhadas de perto. O acompanhamento do crescimento e desenvolvimento indica as condições de saúde e vida da criança, visando a promoção e manutenção da saúde, bem como intervindo sobre fatores capazes de comprometê-la. (SIGAUD,1996)

Quanto à terminologia, crescimento correspondem a fenômenos distintos, embora correlacionados. Crescimento significa aumento do corpo, como um todo ou em algumas de suas partes, e podem ser mensurados em centímetros ou gramas. Significa o aumento do tamanho das células. Desenvolvimento significa capacidade do indivíduo em realizar funções cada vez mais complexas, ou seja, desenvolve controle neuromuscular, destreza e funções que só podem ser mensurados por meio de provas ou testes funcionais.

Uma criança pode crescer e não se desenvolver, e vice-versa. Crescimento e desenvolvimento constituem a resultante final de uma série de fatores, que podem ser divididos em extrínsecos (ambientais) e intrínsecos (orgânicos). Os intrínsecos são representados pela herança genética e pelo sistema neuroendócrino, e os fatores extrínsecos são os fatores ambientais e nutricionais. (MARCONDES,1992)

"O desenvolvimento é a característica primordial da criança que cresce, se modifica e se afirma como indivíduo. Ao atender suas necessidades essenciais, dia a dia, se garante seu crescimento e desenvolvimento harmonioso e se prepara a criança para o futuro. O desenvolvimento significa também saúde. Não pode haver crescimento nem desenvolvimento satisfatório se a saúde da criança está afetada por problemas crônicos, como a desnutrição." (MANCIAUX, 1984, p.238)

Nos países em desenvolvimento, com seus problemas econômicos e sociais, grande parte da população vive em estado de pobreza ou na miséria, com grandes riscos de sobrevivência devido suas condições precárias de vida. Este é um fator ambiental de grande importância a ser estudado, pois dependendo das condições econômicas de um núcleo familiar, pode-se observar, por exemplo a qualidade nutricional em suas refeições, sabendo-se que é pelo alimento que a criança recebe os elementos energéticos e construtivos(são as proteínas) necessários ao seu crescimento. Estes cuidados estão relacionados ao atendimento primário à essa população, que se refere à um atendimento integral e global, isto é, preventivo, curativo e reabilitador, na competência de um médico generalista, com o objetivo de barateamento de custos e a abreviação do atendimento; e a utilização de recursos secundários somente quando o profissional e paciente acharem necessários.
O enfermeiro, como educador em saúde, compartilha com a criança e a família informações e conhecimentos quanto à avaliação de enfermagem da situação da criança; reforça condutas adequadas ao desenvolvimento da criança, dos familiares; e discute propondo alternativas àquelas que julgar inadequadas. Apresentar informações sobre o Crescimento e Desenvolvimento e necessidades infantis, bem como informações que favorecem o crescimento e desenvolvimento da criança. As orientações abrangem características deste, alimentação (quantidade, qualidade e hábitos), higiene, sono, brincadeiras e estimulação, imunizações, formas de comunicação e relacionamento com a criança.

SIGAUD (1996) entendem que o enfermeiro é o profissional de saúde em condições de desenvolver as ações de acompanhamento do crescimento e desenvolvimento, uma vez que tem conhecimento acerca do processo de crescimento e desenvolvimento e das necessidades da criança bem como sobre as formas de atendê-las.

Segundo a Organização Mundial de Saúde, o conceito de nutrição é o processo pelo qual os seres vivos recebem e utilizam as substâncias necessárias à manutenção da vida, ao crescimento, ao funcionamento normal dos órgãos e à produção de energia. Considera-se eutrófica a criança que apresenta estado nutricional normal. Distrofia significa qualquer alteração do estado nutricional normal e compreendem distúrbios da nutrição por carência (anemia, deficiência calórico-protéica) ou por excesso (obesidade).

$\mathrm{Na}$ avaliação clínica do estado nutricional existem alguns fatores importantes que precisam ser levados em consideração:

$3 / 4$ história de doenças (atual e pregressa);

$3 / 4$ história alimentar (atual e passada);

$3 / 4$ exame clínico, medidas antropométricas e descrição de manifestações físicas que expressem deficiências ou excessos nutricionais específicos.

MARCONDES (1996) define desnutrição como sendo uma doença carencial que pode evoluir para a cronicidade, vinculada à idade da lactância, que sob o denominador comum da fome, afeta especificadamente a nutrição e cujo substrato metabólico reside na alteração da função fundamental da célula: o crescimento. Os principais fatores pela desnutrição infantil são a dieta deficiente, infecção, fatores psicológicos, situação sócio-econômica, padrões culturais, nutrição materna e desmame precoce. A prevenção nestas situações são: a organização dos serviços de saúde, educação da equipe de saúde, e educação sanitária; e estas atividades podem e devem ser atribuídas à equipe de enfermagem.

ALCANTARA, (1946) corporificou os princípios gerais que devem reger a alimentação infantil, sendo eles:

$3 / 4$ atender às necessidades energéticas ou quantitativas; 
3/4 ser adequada em relação a intervalos ou horário e número de refeições diárias;

$3 / 4$ apresentar correlação adequada;

$3 / 4$ ser constituída por leite materno nos primeiros meses de vida;

$3 / 4$ corresponder à capacidade digestiva nos vários períodos de desenvolvimento - Introduzir alimentos novos de modo progressivo;

$3 / 4$ ser tão variada quanto possível;

$3 / 4$ ministrar os alimentos com técnica adequada à sua aceitação, bem como à boa formação psíquica da criança.

STEINSCHNEIDER, (1981) propõe que o crescimento normal de uma criança inclui inicialmente um período de crescimento rápido, seguido de uma fase lenta até a puberdade, onde ocorre um período de aceleração. A altura ao nascer é por volta de $50 \mathrm{~cm}$, e o bebê cresce me média $25 \mathrm{~cm}$ no primeiro ano e 15 $\mathrm{cm}$ no segundo, e o peso ao nascimento é de aproximadamente $3.300 \mathrm{~g}$, dobrando de peso aos cinco meses e triplicando ao fim do primeiro ano de vida, e a partir do primeiro ano o ganho ponderal médio é de 2 a $3 \mathrm{Kg}$ até o estirão pré-pubertário, dos nove aos 10 anos.

Portanto, é importante a realização do exame clínico da criança de maneira detalhada para que se consiga detectar precocemente qualquer agravo e mesmo preveni-lo para que não ocorra distúrbios nutricionais. Para tanto, faz-se necessário uma investigação sobre o hábito alimentar da família, pois com certeza influenciará no estado nutricional e no desenvolvimento da criança e do adolescente; além da importância de estudar a criança em todo seu contexto, observando e analisando-a integralmente todas as características físicas, sociais e psíquicas.

Considerando todos estes aspectos, interessamos ter como objeto de estudo crianças na faixa etária de 12 a 48 meses de idade matriculadas em uma creche na periferia da cidade de Ribeirão Preto.

\section{OBJETIVO}

Este trabalho tem como objetivo descrever a característica estrutural e funcional de uma creche Municipal que atende crianças na faixa etária de 12 a 48 meses de idade, na periferia da cidade de Ribeirão Preto-SP, e também conhecer e descrever o estado nutricional e situação social dessas crianças matriculadas na referida creche no ano de 2000

\section{PERCURSO METODOLÓGICO}

O foco principal deste estudo está no interesse de conhecer a realidade das crianças que passam a maior parte do dia em uma creche, e ampliar esse conhecimento em seus ambientes familiares, seus hábitos, e suas dificuldades.

A pesquisa é do tipo exploratória e descritiva (TRIVIÑOS,1992). Com o intuito de aprofundar a descrição de determinada realidade, optamos por elaborar um "Estudo de Caso" a respeito da situação nutricional e social de 58 crianças matriculadas na creche de Ribeirão Preto, e realizar um trabalho exploratório a fim de identificar casos de distúrbios nutricionais relacionados às condições sociais das mesmas.

Os instrumentos de coleta de dados utilizados para avaliação do crescimento e desenvolvimento foi a somatometria (peso/estatura); observação do ambiente no espaço da creche e no contexto familiar durante as visitas às residências; entrevista semiestruturada com os pais.

Para verificação do peso, utilizou-se balança de graduação com capacidade adequada para o tamanho da criança. Crianças com até $16 \mathrm{Kg}$ foram pesadas em balança cuja graduação mínima é de $100 \mathrm{~g}$, na posição deitada ou sentada. Acima deste peso, as crianças foram pesadas em balança de adulto, com graduação de $100 \mathrm{em} 100 \mathrm{~g}$, na posição em pé ou no colo. Quando houve necessidade de pesar no colo, pesou-se o adulto primeiramente, e depois pesou-se ele com a criança no colo, e obtevese o peso da criança pela diferença dos valores encontrados. Durante a pesagem, as crianças pequenas estiveram totalmente despidas, e as maiores trajando apenas roupas de baixo.

Para a verificação da estatura da criança com até $100 \mathrm{~cm}$, utilizamos o antropômetro posicionando a criança em decúbito dorsal e com as pernas estendidas. O ramo fixo do antropômetro foi mantido junto ao ápice da cabeça da criança e o móvel, ajustado ao seu calcanhar. As crianças maiores foram medidas em pé, com a régua vertical. Foram mantidas descalças, de costas junto à régua, em posição ereta com os braços ao lado do corpo e cabeça voltada para a frente, e ajustando ramo móvel da régua ao ápice da cabeça da criança. (SIGAUD, 1996). Para uma melhor interpretação dos resultados, foram realizadas medições a cada 2 meses durante o ano 2000.

Os dados colhidos, foram colocados no gráfico de crescimento proposto por MARCONDES (1992). Para cada sexo existe um gráfico que contém curvas de peso e altura. Para ambos os indicadores, foram estabelecidos duas curvas como parâmetro: a superior corresponde ao percentil 90 e a inferior ao percentil 10, e os valores compreendidos entre elas são considerados satisfatórios.

Em visitas às famílias dessas crianças, foram realizadas entrevistas semi estruturadas a respeito de condições sócio-econômicas (renda familiar), número de habitantes na residência, escolaridade e hábitos alimentares, tanto da família como da criança.

\section{CAMPO DE ESTUDO}

A pesquisa foi realizada na cidade de Ribeirão Preto, na Creche Municipal Branca Serra, situada no bairro Alexandra Balbo, na periferia da cidade.

O município de Ribeirão Preto localiza-se na região nordeste do Estado de São Paulo, ocupando uma área total de $651 \mathrm{Km}^{2}$, constituindo-se de um 
dos mais importantes centros de desenvolvimento econômico e cultural do interior paulista. O município abrange uma ampla rede de serviços de saúde de naturezas diversas (pública, filantrópica e privada) compreendendo a área de atenção primária, secundária e terciária. Devido à complexidade de recursos nestas áreas, o município representa um centro médico de referência para toda a região, e, em alguns casos, a outros estados do país. É sede da DIR XVIII, que abrange 23 municípios. A rede do município é formada por serviços estaduais, pela rede municipal, por serviços filantrópicos e particulares conveniados. Fazem parte também desta rede as Faculdades de Medicina, Odontologia, Ciências Farmacêuticas, Enfermagem, Psicologia da USP, e algumas Faculdades particulares como: Odontologia, Fisioterapia e Ciências Farmacêuticas da Universidade de Ribeirão Preto (UNAERP) e Ciências Biomédicas da Faculdade Barão de Mauá.

O modelo de assistência à saúde existente hoje no Município é do tipo clínico assistencial com tendência à especialização, medicalização, e sofisticação tecnológica; isto é valido para os setores: municipal, estadual, conveniado e privado.

O município foi dividido em setores e subsetores, baseado no decreto $\mathrm{n}^{\circ} 333$ de 26 de dezembro de 1983 da Prefeitura Municipal de Ribeirão Preto. O objetivo desta divisão prendeu-se ao fato de que se pudesse com maior precisão, realizar levantamentos de densidade demográfica, definição de zonas residenciais, comerciais e industriais, ou seja, para obter com maior clareza dados indispensáveis ao planejamento de atividades relacionadas à saúde, à educação, ao saneamento, abastecimento, transporte e outros.Entende-se por setor a divisão do distrito em cinco áreas distintas, delimitadas por acidentes geográficos, barreiras físicas e vias de tráfego pesado, localizadas de acordo com os seguintes quadrantes: $\operatorname{Norte}(\mathrm{N})$, Leste(L), Sul(S), Oeste(O) e Central(C).

Pode-se observar então, que Ribeirão Preto detém aspectos que a caracterizam como uma das cidades mais prósperas do interior paulista, embora não possamos perde de vista seus traços marcantes de subdesenvolvimento, pobreza e miséria. Há grande preocupação pelos bairros periféricos onde o índice de criminalidade e precariedade são altos, provavelmente pelo fato de Ribeirão Preto fazer parte da "Rota Caipira" do narcotráfico.

A creche situa-se em um desses locais, no Bairro Alexandre Balbo. O índice de criminalidade é alto, há muita pobreza, dificuldades e medo desses moradores. As preocupações deles estão em torno da violência, falta de emprego, e discriminação social e moral.

\section{ANÁLISE DOS RESULTADOS}

\section{Características da creche}

A creche é do governo municipal antes ligada à Secretaria do Bem-Estar Social, mas atualmente é mantida pela Secretaria da Educação, atendendo preferencialmente crianças cujas mães trabalham fora e não tem com quem deixar seus filhos. A finalidade da creche não é apenas deixar a criança em local seguro enquanto a mãe trabalha; também tem prioritariamente o objetivo de proporcionar estímulo de suas capacidades psico, motoras, físicas e sociais para seu desenvolvimento integral. Para isso, é preciso que a equipe possua conhecimento sobre crescimento, desenvolvimento para assistência global da criança a fim de desenvolver atividade pedagógicas de acordo com a faixa etária, e também observar características anormais em relação a algum aspecto do desenvolvimento, seja físico, motor ou psicológico das crianças, sendo para isso extremamente necessário treinamentos abrangendo todas essas áreas para que a criança seja vista como um todo, integrada dentro de uma sociedade.

A creche Branca Serra tem capacidade para 60 crianças, contando com 10 funcionários, sendo 2 cozinheiras, uma auxiliar de serviços, 6 educadoras e uma coordenadora que fornece o suporte pedagógico, não havendo acompanhamento fixo de um profissional da saúde. A maioria das educadoras está cursando Magistério, e a Coordenadora está cursando Pedagogia. Apesar dos esforços da Coordenadora, foram constatados poucos estímulos pelas educadoras e dificuldade delas em aceitar a visão integral da criança. A cultura de que crianças pré- escolares não necessitam de estímulos é forte, e muitas acreditam ser desnecessário, e a creche é apenas um local para abrigá-las enquanto as mães trabalham. Quanto às atividades de lazer, são programadas semanalmente para as turmas, mas o espaço é limitado, e as atividades se restringem às brincadeiras no playground, e nos dias de chuvas, as crianças permanecem nas salas de aulas.

Conta com o espaço físico de 3 salas de aula, 1 sala da coordenação, almoxarifado, 2 banheiros infantis, 1 banheiro para funcionários, 1 refeitório, 1 tanque de areia com playground. Quanto à higiene da creche, a limpeza é realizada uma vez por semana com água e sabão, e diariamente com solução desinfetante. As caixas d'água são limpas uma vez por ano e o jardim é limpo quando solicitado à frente municipal de trabalho "Cidade Limpa". A areia é trocada a cada 6 meses. Os brinquedos são lavados semanalmente com sabão e as chupetas são descontaminadas com água e sabão. É feita ronda policial diariamente, e a creche não conta com vigia noturno.

Em relação à alimentação, são oferecidas 5 refeições diárias no sistema self-service, onde as crianças escolhem o que desejam comer, desperdiçam alimentos, não havendo orientação pelas educadoras a respeito da importância nutricional de todos grupos de alimentos que algumas crianças se recusam a comer. O cardápio é elaborado pela Divisão Nutricional Municipal. 
CARABOLANTE, A. C.; FERRIANI, M. G. C.; O crescimento e desenvolvimento de crianças na faixa etária de 12 a 4832 meses em creche na periferia da cidade de Ribeirão Preto - SP. Revista Eletrônica de Enfermagem, v. 5 n. 1 p. 28 - 34 , 2003. Disponível em http:/www.fen.ufg.br/Revista.

\section{Caracterização das crianças matriculadas na creche e de suas famílias}

São 58 crianças, na faixa etária entre 12 a 48 meses, que passam aproximadamente 9 horas diárias na creche. São oriundas de famílias de baixa renda, em média de 4 a 5 filhos; maioria dos familiares desempregados ou com emprego informal ( as ocupações variam entre empregadas domésticas, ajudantes de serviços gerais ou funcionários da Prefeitura Municipal na limpeza da cidade - os "garis"), com renda mensal de 2 a 3 salários mínimos; alto índice de analfabetismo, e escolaridade entre $1^{\circ}$ e $2^{\circ}$ graus incompletos. As moradias apresentam graves problemas de saneamento básico, e algumas estão ainda em aquisição.

Há serviço de esgoto, mas as residências são cercadas por lixo e mato, que podem provavelmente transmitir doenças e não há conscientização desse risco.Outra situação observada foi o número de cômodos pequeno em relação ao número de moradores. Existem famílias onde as crianças dormem no mesmo quarto ou na mesma cama, ignorando qualquer sentimento das crianças. $O$ alcoolismo também é muito presente nessas famílias, e em muitos casos as crianças podem ser vítimas de seus próprios pais. Além do alcoolismo, o uso de drogas propiciam a violência familiar, gerando conflitos que possivelmente influenciarão no processo de desenvolvimento dessas crianças.

A característica mais marcante é a carência afetiva devido esta falta do relacionamento familiar saudável; algumas sendo até agressivas, reproduzindo atitudes aprendidas em casa com os seus. Todas as crianças têm pouca iniciativa para atividades comuns devido pouco estímulo recebido seja na creche, ou em casa. Algumas se isolam, preferindo não participar das brincadeiras, outras têm medo de serem repreendidas, atitude esta que pode ser reflexo da situação que se encontram. Enfim, pode-se observar que a relação social e educacional está estreitamente ligada na formação de um adulto durante a infância.

\section{Resultados do estado nutricional das crianças}

Através da somatometria (relação entre peso e estatura), e segundo parâmetros estabelecidos foi possível obter os seguintes dados a respeito do estado nutricional das crianças:

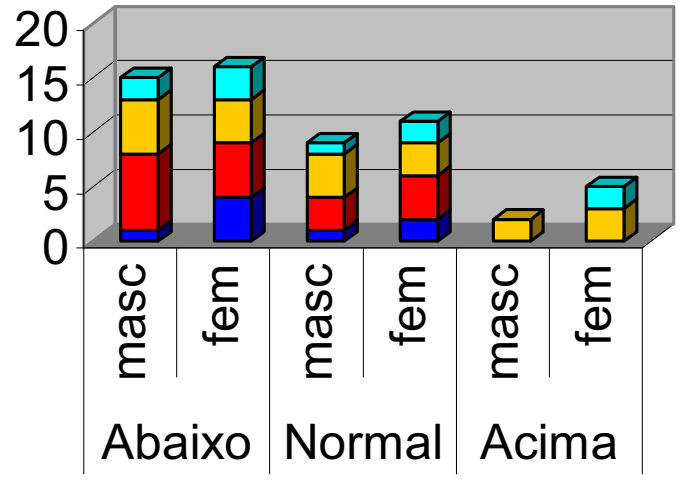

$\square 48$ Meses

$\square 36$ Meses

$\square 24$ Meses

12 Meses
No total, observa-se que $53,4 \%$ das crianças estão abaixo do P10, sendo que destas 48,3\% encontram-se na faixa etária de 24 meses; 34,4\% estão no índice de normalidade, e $12 \%$ estão acima de P90; ou seja, o maior contingente (mais da metade) está com alguma alteração em seu crescimento, segundo os parâmetros normais.

Segundo a relação entre idade e estado nutricional, obtemos a porcentagem da situação nutricional: 


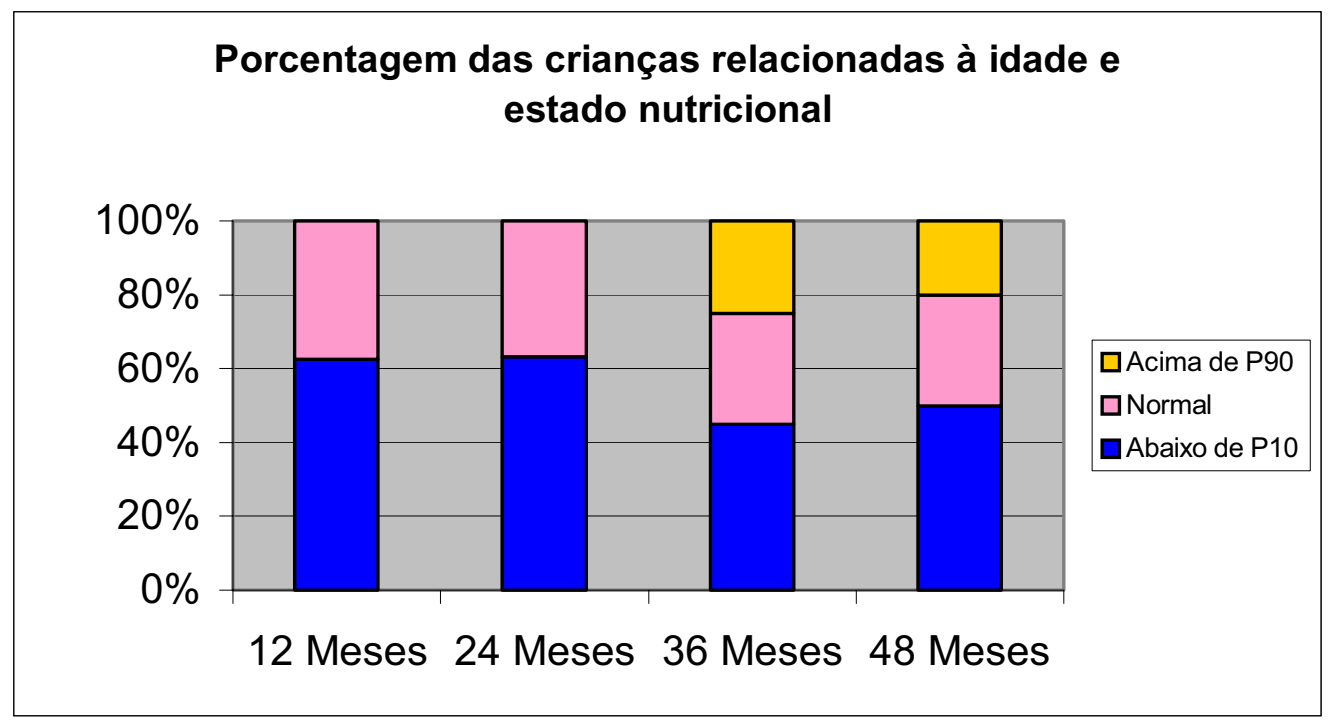

Observa-se que do total das crianças na faixa etária de 12 meses, $62,5 \%$ estão abaixo de p10 enquanto $37,5 \%$ estão no índice de normalidade. Do total das crianças na faixa etária de 24 meses, $66,6 \%$ estão abaixo de $\mathrm{P} 10$, e $38,8 \%$ estão no índice de normalidade. Do total das crianças na faixa etária de 36 meses, $42,8 \%$ estão abaixo de P10, 28,5\% estão no índice de normalidade, e $23,8 \%$ estão acima de $\mathrm{P} 10$. Do total das crianças na faixa etária de 48 meses, $50 \%$ estão abaixo de P10, 30\% estão no índice de normalidade, e $20 \%$ estão acima de P90.

Em relação às crianças abaixo de $\mathrm{P} 10$, segundo a idade, obtemos os seguintes resultados:

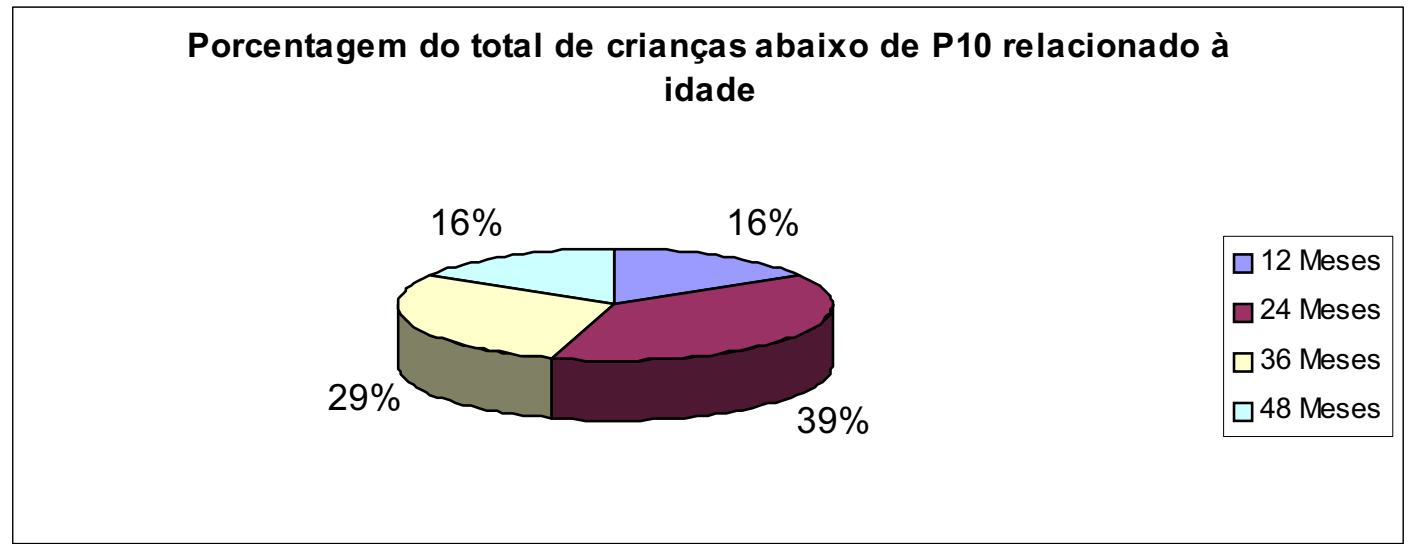

De acordo com os resultados obtidos, foram realizadas visitas domiciliares às famílias das 31 crianças abaixo do Percentil 10. Constatou-se que não há interesse a respeito do crescimento e desenvolvimento integral e muito menos do estado nutricional deficiente de seus filhos, alegando outros problemas para preocupam a família, como pode ser evidenciado abaixo:

"Aqui a gente tem que ver se vai ter comida pra amanhã, se vai ter dinheiro pra remédio, e quando meu filho mais velho não carece de dinheiro pra pagar os traficante, senão ele morre...

Pode deixar que essa molecada cresce sozinha." (F1)

Percebe-se que a preocupação está em torno da sobrevivência, outras preocupações são dispensáveis e/ou supérfulos. Com esses dados pudemos concluir que as dificuldades marcam as vidas dessas pessoas, que estão sempre preocupados com seus sustentos, com a violência (pois a qualquer momento qualquer um pode ser uma vítma dela), drogas, a própria discriminação social imposta pela sociedade (falta de emprego, discriminação devido baixa escolaridade, apresentação pessoal, cor da pele, etc) além de muitas outras dificuldades, que muitas vezes esses pais apavorados e preocupados se esquecem de acompanhar todo o processo de crescimento e desenvolvimento de seus filhos, e não raramente negam essa importância.

Há um estilo de música próprio da periferia, o "Rap", que descreve a realidade de vida deles numa visão bem própria deles, e há um trecho que diz:

"...seria diferente se eu fosse mauricinho; criado a Sustagem e Leite Ninho 
colégio particular, depois faculdade, mas não, não é essa a minha realidade

sou caboclinho comum

com sangue no olho, com ódio na veia

soldado do morro

feio esperto com uma cara de mal, a sociedade me criou mais um marginal

eu tenho uma 9 e uma HK [modelos de metralhadoras]

com ódio na veia, pronta para atirar ..." ("Soldado do Morro", MV Bill)

Este trecho traduz a violência e a revolta contra a sociedade que eles acreditam que é a culpada por todas suas dificuldades. Essa é uma realidade muito próxima dessas crianças, que desde muito cedo convivem com esses problemas sociais, e podem revoltar-se mais tarde, tornando um ciclo vicioso, pois toda essa revolta provavelmente vão transmitir aos filhos, que sofrendo a discriminação e somando às condições reais de sobrevivência, passarão a também se perguntar porque devem ser excluídos dessa forma tão traumática e dolorosa da sociedade, e finalmente acabam se revoltando contra ela.

Ao grupo de crianças abaixo de P10, foram dadas explicações aos pais e responsáveis a respeito da importância do acompanhamento do desenvolvimento global de seus filhos, desde a alimentação ao cuidado emocional e afetivo. Foram orientados com medidas caseiras para prevenção de doenças e soluções de problemas de saúde, assim como métodos contraceptivos a fim de evitar o crescimento não planejado da família já numerosa. Foi articulado com a UBS local a possibilidade do atendimento dessas crianças, em comum acordo com a Coordenadora da creche a fim de proporcionar um suporte permanente à saúde, principalmente direcionado à prevenção de doenças e agravos.

\section{CONCLUSÃO}

Este estudo realizado em uma creche municipal na periferia de Ribeirão Preto com o objetivo de conhecer o estado nutricional e as interações sociais das 58 crianças matriculadas, mostrou que $53,4 \%$ das crianças estão abaixo do P10, sendo que destas $48,3 \%$ encontram-se na faixa etária de 24 meses.

Em relação ao meio social e às famílias dessas crianças, foi observado através de visitas domiciliares grande pobreza e precariedade em suas residências. Há grandes dificuldades relacionadas ao desemprego, alto índice de criminalidade devido narcotráfico e exclusão social. Os pais alegam não se preocuparem com seus filhos, pois "eles crescem sozinhos" (sic). Portanto, a presença da enfermeira nesse contexto é de grande importância, pois o crescimento infantil e o desenvolvimento psíquico e social refletirão na formação de um cidadão, humano e consciente, amenizando quadros desfavoráveis a partir da educação em saúde, conscientização de seus papéis na sociedade e a importância de suas responsabilidades.

\section{BIBLIOGRAFIA}

AlCANTARA, P. Causas e Remédios Sociais da Mortalidade Infantil São Paulo, Rev. Tribunais, 1975.

MANCIAUX, M. Requisitos para um desarrollo armonioso. Boletín de la Oficina Sanitária Panamericana (OPS), PAHO Coll, 1984.

MARCONDES, E. Pediatria básica, $8^{\circ}$ ed. São Paulo, Savier, 1992, v.1 e 2.

SIGAUD, C.H. Enfermagem pediátrica. São Paulo: EPU, 1996.

STEINSCHNEIDER, R. Cadernos de enfermagem Pediatria. RJ - Masson, 1981.

TRIVIÑOS, A. N. S. Introdução à Pesquisa em Ciências Sociais: a pesquisa qualitativa em educação. São Paulo, Editora Atlas, 1992.

Texto original recebido em 23/03/2003

Publicação aprovada em 27/06/2003 